\title{
Augmentation on Heat Transfer and Friction Factor in Three Sides Solar Air Heaters Having an Arrangement of Multi-V and Transverse Wire Roughness on the Absorber Plate
}

\author{
Dhananjay Kumar $^{1^{*}}$, Laljee Prasad ${ }^{1}$ \\ ${ }^{1}$ Mechanical Engineering Department, National Institute of Technology, \\ Adityapur, Jamshedpur 831014 Jharkhand (India) \\ Email: dhananjaykumar84nit@gmail.com
}

Received 17 September 2020, Revised 25 March 2021, Accepted 1 April 2021

\begin{abstract}
This paper present the experimental inquiry on heat transfer and friction features enrichment adopting new-fangled of three side's synthetically rugged rectangular duct solar air heaters (SAHs). The roughened rectangular SAH ducts has been an arrangement of multi-v and transverse wire (top wall multi-v and two side walls transverse) covered with glass on three sides. It has various appliances such as crop drying, seasoning of timber, space heating, industrial purpose, etc. The rectangular duct used has a width to height ratio, $\mathrm{W} / \mathrm{H}$, equal to 8 , relative raggedness pitch, $\mathrm{P} / \mathrm{e}$, wide-ranging from $10-25$, relative raggedness height, e/D, varied from $0.018-0.042$ and flow Reynolds number, Re, occupied from $3500-12,000$ for fixed values of relative raggedness width, W/w, of 6 and an angle of attack, $\alpha$, equal to $60^{\circ}$. The heat transmission and friction features of this roughened duct is compared with plane ones under identical working conditions. The maximum augmentation in heat transmission and friction feature is identified to be 6.42 and 6.44 times over the smooth duct respectively. The enhancement in air temperature streaming under three side's synthetically rugged SAH duct is found to be $54.47 \%$ more than that of the smooth one. Three side's artificially rugged rectangular duct SAHs are preferable over plane ones collectively and tentatively
\end{abstract}

Keywords: Artificial roughness; airflow; heat transmission; pressure drop; solar energy; solar air heaters.

\section{Introduction}

Energy is the basic need for a human being it is a prime agent for the economic development of any country. It may be classified in two ways conventional (non-renewable) and non- conventional (renewable) energy resources. Solar energy is the spirited energy of all non-conventional sources but its practice expanses is very deficient. It is the most imperative renewable source of energy as it gives nonpolluting climate-friendly output and is available in sufficient [1-2]. It has a lot of applications in thermal energy operation schemes, like solar water warmer, the air warmer, the solar cooker, pump, electric power generation, etc. Among numerous functions of solar energy, air heating through SAHs is a very modest and cost-effective way. Solar air heaters (SAHs) are generally used for low to medium grade thermal energy, like space heating, crop drying, seasoning of timber and industrial purpose, etc. Its maintenance and operating costs are low and design is very simple [3-7]. The schematic representation of the conventional SAH is shown in Figure 1. Its efficiency is low due to poor thermo-physical properties of air and low rate of heat transfer coefficient between absorber plate and air flowing in the duct. The experiment follows to augment the rate of heat transfer adopting fabricated raggedness in the form of reciprocated wires under the surface of the absorber plate. The use of fabricated raggedness on a facade is an active and monetary method for augmenting the amount of heat transfer to the air blowing in the duct [8-9]. Han et al. [10] inspected the conclusion of the rib model, flow attack angle, and pitch to rib height ratio on friction features and heat transmission of a rectangular duct with two sides' rugged walls, and also informed that the maximum values of heat allocation and friction feature can occur at $\mathrm{P} / \mathrm{e}$ morals of 10 , and rib inclined at $45^{\circ}$ angle. Taslim et al. [11] reported the heat transmission and friction features of a channel rugged with oblique and v-shaped ribs. They originate that v-shaped ribs indicating down-stream have greater heat transfer as related to that of v-shaped ribs indicating upstream. Goa and Sunden [12] also testified that v-shaped ribs facing down-stream superior to the ribs facing up-stream in four-sided ducts. Saini and Saini [13] stated for fixing wire net on the absorber plate as a roughness and examined the outcomes of the relative long-way and relative short-way length of mesh on heat transmission and friction features. Prasad et al. [14] reported with arrangements for the optimization of thermo-hydraulic enactment in three sides synthetically rugged SAHs and described the assumption of optimal thermo-hydraulic enactment for every set of the values of raggedness and flow limitations as e/D, P/e, and flow $\mathrm{Re}$, authors also found that an optimum thermohydraulic enactment in three sides rugged SAHs and conclude that it gives higher heat transmission as related to only one side rugged SAHs. Behura et al. [15] described the empirical outcomes on heat assignment, friction feature and thermal enactment of a unique variety of three side's synthetically rugged SAHs and equated with one side rugged SAH under the identical working situation. They found that such SAH has greater values of heat transmission factor than that of one side synthetically rugged SAHs in the range of $21-78 \%$ for the equal morals of the working specification. Kumar and Prasad [24] established the 
outcomes for adopting dimple shaped rugged SAHs and informed that for improvement in $\mathrm{Nu}$ is strongly associated with raggedness and drift restrictions. The concentrated enrichment in heat transmission for changeable relative dimple pitch $(\mathrm{P} / \mathrm{e})$, relative dimple height $(\mathrm{e} / \mathrm{D})$ and relative dimple depth (e/d) were separately established in the order of 2.6-3.55, 1.91-3.42 and 3.09-3.94 moment with equated to 1 - side synthetically rugged duct. The extreme morals of the thermal efficiency for 1-side and 3-sides rugged $\mathrm{SAH}$ are initiated as 0.55 and 0.89 individually, conforming to the peak raggedness limitations at $\mathrm{P} / \mathrm{e}=12$, $\mathrm{e} / \mathrm{D}=0.036$ and $\mathrm{e} / \mathrm{d}=1.5$ in the kind of inspected restrictions. Perwez and Kumar [25] experimentally conducted to regulate the thermal enactment of a spherical dimple plate solar air heater (SDPSAH) and a flat plate solar air heater (FPSAH) at distinctive ecological situations for a mass stream rate of air changing from $0.009 \mathrm{Kg} / \mathrm{s}$ and 0.028 $\mathrm{Kg} / \mathrm{s}$. They observed that the SDPSAH expresses the higher heat transfer rate, which is about 1.51 to 1.64 times higher than the comparable FPSAH. The maximum rise of the outlet temperature of the SDPSAH is about $4.6{ }^{\circ} \mathrm{C}$ larger than the corresponding FPSAH for $0.009 \mathrm{~kg} / \mathrm{s}$ mass stream rate of air. The instantaneous thermal efficiency of the SDPSAH is about $23.45 \%$ to $35.50 \%$ greater than the analogous to FPSAH. The different types of ribs raggedness arrangement has been presented in Table 1 .

From the literature survey, it has been identified that the heat transmission on the ribbed wall having one-side ribs about $2-3$ times higher than four-sided smooth duct [22-23, 2728]. In the recent work, empirical analysis on heat transfer and friction features of new-fangled rectangular duct SAHs, having the absorber plate with three-sides synthetic raggedness in the arrangement of a grouping of multi- $v$ and transverse wire (top wall multi-v and two-side walls are transverse) ribs have been drifting out, a smooth SAH operating under similar conditions has to be considered for comparisons. The main objective of this paper is to inspect the imports of relative raggedness pitch $(\mathrm{P} / \mathrm{e})$, relative raggedness height (e/D) at variable standards of drift Reynolds number (Re) on heat transfer and friction features for 3-sides synthetically rugged SAHs and find the dominant performing restrictions to describe the benefit of this selected raggedness geometry.

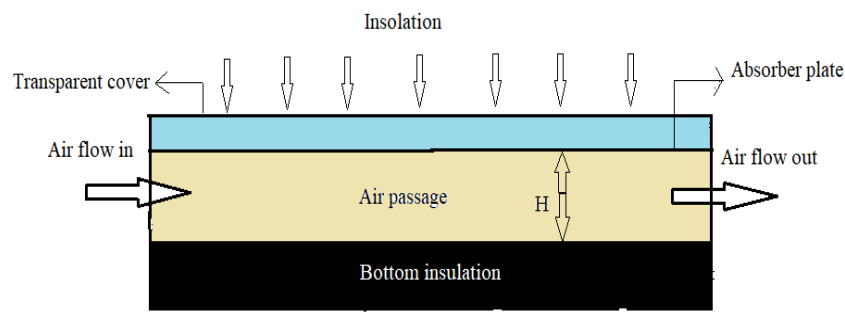

Figure 1. Schematic representation of conventional solar air heater.

\section{Experimental Details}

\subsection{Experimental Set-up}

The tentative investigation facility has been framed and composes to study the outcome of an arrangement of multiple-v and transverse wire-shaped raggedness geometry on the heat transmission and friction feature of a four-sided SAH ducts. A schematic representation of the experimental set-up has been shown in Figure 2. The experimental setup was frame, as per American Society of Heating,
Refrigerating and Air-Conditioning Engineers (ASHRAE) standard 93-77 [19] for measuring the enactment restrictions of roughened solar collectors under authentic outdoor situations employing open loop arrangement. The ASHRAE standard is an international association that worked for the exclusive purpose of advancing the arts and sciences of HVAC \& R (heating, ventilation, airconditioning, and refrigeration), the allied arts and sciences, and the related human factors for the benefit of the public. The trial set-up contained three ducts equivalent to each other, especially $\mathrm{X}, \mathrm{Y}$, and Z. The photographic outlook representation of the experimental set-up has been revealed in Figure 3. The recent tentative inquiries operate the duct $Y$ and $\mathrm{Z}$ involve smooth and three sides rugged solar collector respectively. It contains an unheated bell mounted entrance region, heated test passage, exit region, transition region, a flow computing orifice-meter and a centrifugal-blower with an electric motor. Wood has been adopted over other materials to frame the bottom of the duct as it is inexpensive, comfortably obtainable and also has to isolate properties. For measuring the mass discharge rate of air over the duct, a rectified orifice-meter linked to a willing U-tube manometer was used. The pressure descent beyond the trial region was notified employing a micro-manometer taking the tiniest amount of $0.001 \mathrm{~mm}$ of the $\mathrm{H}_{2} \mathrm{O}$ column, where the hotness of the absorber plate at several positions was dignified with standardized $0.3 \mathrm{~mm}$ diameter Copper-constantan thermocouples joined to differential micro-voltmeter to illustrate the temperature. Twelve thermocouples stayed used to measure the degree of hotness of the topmost and lateral faces of the plate at distinct localities. The temperature of the air blowing over the duct is measured by a digital thermometer. The plate of duct being 22 standard wire and gauge galvanized (SWG) iron sheet of thickness $0.6 \mathrm{~mm}$ has been used for solar collectors having dimensions of $2 \mathrm{~m} \times$ $0.2 \mathrm{~m} \times 0.025 \mathrm{~m}$ coated black. Synthetic roughness was composed on the basement of the plate by fix galvanized iron wires in the form of a grouping of multi-v and transverse wire (top wall multi $-\mathrm{v}$ and two side walls transverse) has been exposed in Figure 4. Photographic representation of absorber plate are revealed in Figure 5. The intensity of solar insolation is dignified with the support of a digital pyranometer as revealed in Figure 9.

\subsection{Experimental process}

The trial facts were possessed for an arrangement of multi-v and transverse wire roughened duct pertaining Nusselt number and friction factor as per the suggestion of ASHRAE Standard 93-97 [19]. The rugged absorber plates were framed for distinct rib specifications as declared in Table 2. The testing statistics were composed for 12 groups of the rugged absorber plate and 60 numeral of a trial run for both smooth and three-side's synthetically rugged SAHs. For every trial run, originally all instrument viz., inclined U-tube manometer, micro-manometer, voltmeter, and ammeter, were verified to avoid any air leakage [29]. In the initiation, a steady-state was achieved in $3-4$ hour. The entire tentative work can be carried out under actual open-air surroundings. For a particular day, information was composed for a specified ethical of mass flow rate under fluctuating morals of solar insolation within intermission of 15 minutes in-between 11:00-14:00 hour on clear sky day. During the trial period, the intensity of solar insolation wide-ranging from $709-919 \mathrm{~W} / \mathrm{m}^{2}$ and ambient temperature varied from $36.9-41.7^{\circ} \mathrm{C}$ on a particular day. 
The hydraulic diameter of both smooth and 3-sides rugged solar collector is driven out to be $44.44 \mathrm{~mm}$, as the ducts are preserved parallel in magnitudes.

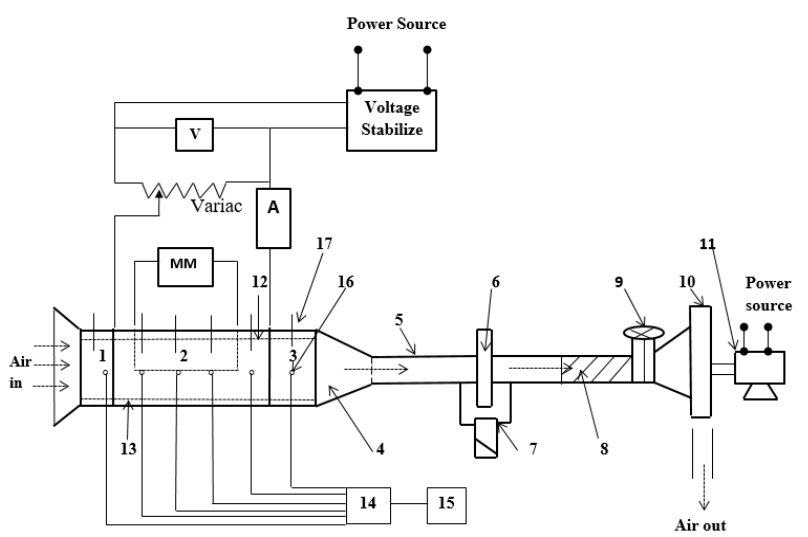

1. Unheated entry segment, 2. Heated test sector, 3. Exit region, 4. Transition section, 5. Flow pipe, 6. Orifice meter, 7. Inclined U-tube Manometer, 8. Flexible pipe, 9.Gate valve 10. Blower, 11. Electric motor, 12. Absorber plate 13. Bottom of duct, 14. Selectors switch, 15. Temperature recorder, 16. Thermocouple, 17. Digital thermometer, A- Ammeter, V- Voltmeter, MM- Micro-manometer.

Figure 2. Schematic representation of experimental setup.

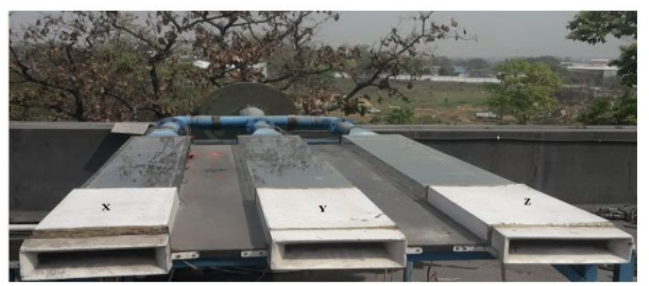

$\mathrm{X}$. One side roughened solar air heater duc

Y. Smooth solar air heater duct,

Z. Three sides roughen solar air heater duct
Table 1. Different type's arrangements of the ribs.

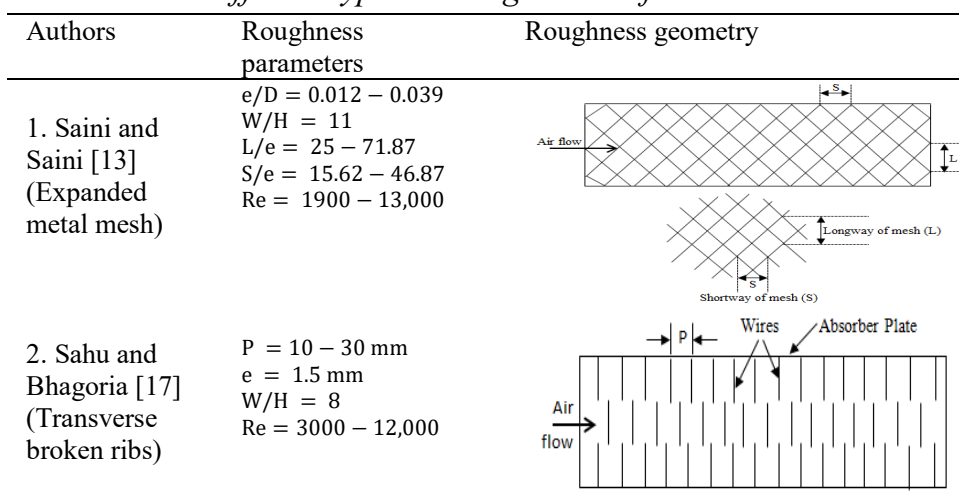

\section{Karwa et al $\quad \mathrm{P} / \mathrm{e}=4.58-7.09$ [18] (Integral $\quad \mathrm{e} / \mathrm{D}=0.0197-0.0441$ chamfered ribs) $\quad \emptyset=15^{\circ}$}

$\operatorname{Re}=3750-16530$

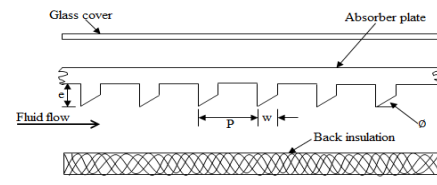

$\begin{array}{ll}\text { 4. Karwa and } & \mathrm{P} / \mathrm{e}=10.63 \\ \text { Chitoshiya }[20] & \mathrm{B} / \mathrm{S}=6 \\ \text { (Discrete } \mathrm{V}- & \mathrm{w} / \mathrm{e}=2.06 \\ \text { down rib } & \alpha=60^{\circ} \\ \text { roughness) } & \mathrm{W} / \mathrm{H}=7.8 \\ & \mathrm{e} / \mathrm{D}=0.047 \\ & \mathrm{Re}=2500-18,000\end{array}$

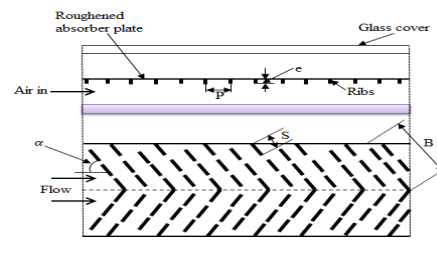

5. Layek et al $\quad \mathrm{P} / \mathrm{e}=4.5-10$

$\mathrm{e} / \mathrm{D}=0.022-0.04$

(Transverse $\quad \mathrm{g} / \mathrm{P}=0.3-0.6$

chamfered rib- $\quad \emptyset=5-30^{\circ}$

$\operatorname{Re}=3000-17,000$

groove

roughness)

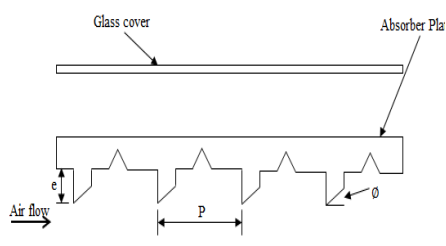

Figure 3. Photographic representation of experimental set-up.
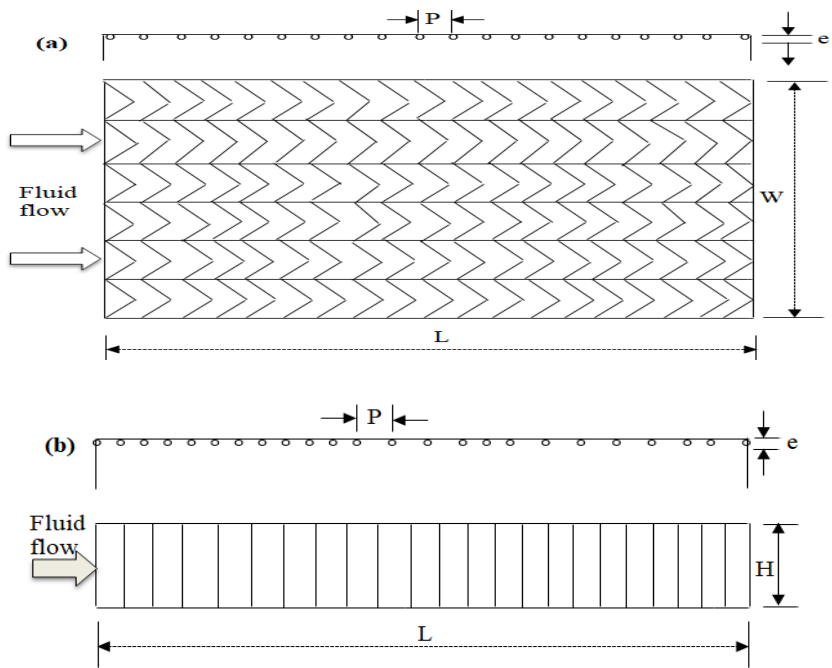

Figure 4. (a). Top absorber plate (b). Side absorber plate in three side's rugged duct.

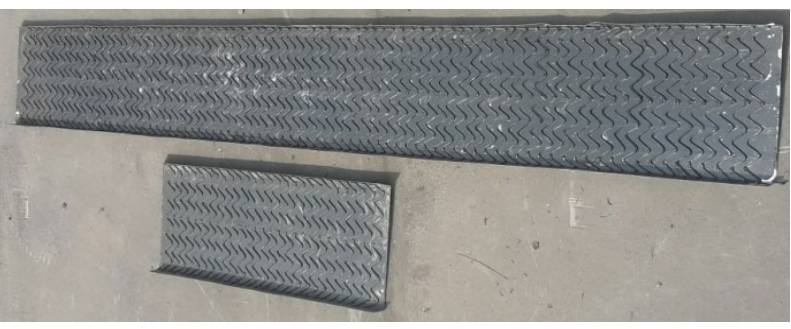

Figure 5. Photographic representation of absorber plate.

\section{Instrumentation}

\subsection{Blower and Electric Motor}

The climatic air was sucked through a $\mathrm{SAH}$ duct arrangement using a blower powered by a 3 -phase ( 5 H.P) induction motor. The power of the motor has to be such that it is capable of sucking the air at the same time in all three duct arrangements at changing mass stream rate to provide the Reynolds number in the collection of $3000-50,000$.

\subsection{Air Flow Measurement}

The air-stream measurement was consummated by a calibrated flange-taps type orifice-meter which was deliberate, fabricated and finally fitted in the $76.2 \mathrm{~mm}$ diameter tube that carried the air-flow from the duct arrangement. The mass stream rate through the orifice-meter is articulated in the terms of physical constraints of the orifice-meter and the pressure alteration across it. The pressure descent across the test segment $\left(\Delta \mathrm{P}_{\mathrm{d}}\right)$ was measured by a multi-tube manometer having a least count of $0.01 \mathrm{~mm}$ of $\mathrm{H}_{2} \mathrm{O}$ column. To measure the pressure descent across the test segment, the pressure indicators were fed to the multitube manometer through PVC piping devoted to the pressure taps of $6 \mathrm{~mm}$ diameter PU-hose connectors inserted along the centre-line of the bottom side of the conduit. The representation of pressure taps location in the SAH conduit has been revealed in Figure 6. The importance of pressure descent was used to measure the friction feature and pumping power exhausted in the duct during movement of air. 


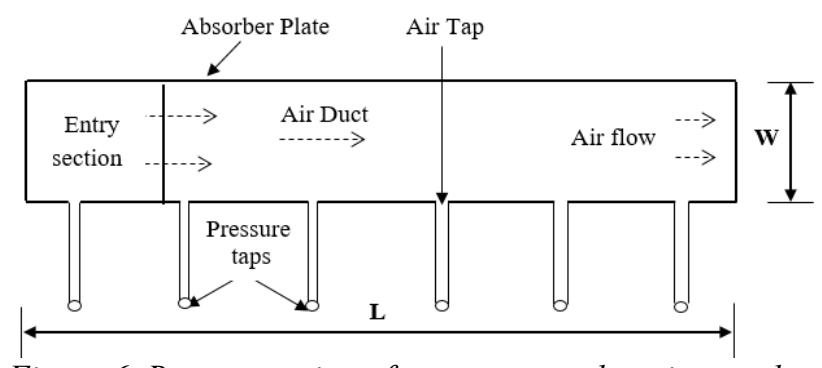

Figure 6. Representation of pressure taps location on the air duct.

Table 2. Standards of roughness and flow limitations

\begin{tabular}{ll}
\hline Parameter & Values \\
\hline Relative raggedness pitch, (P/e) & $10-25$ \\
Relative raggedness height, (e/D) & $0.018-0.042$ \\
Angle of attack, $(\alpha)$, degree & $60^{\circ}$ \\
Relative raggedness width (W/w) & 6 \\
Reynolds number , (Re) & $3500-12,000$ \\
\hline
\end{tabular}

\subsection{Temperature Measurements}

The digital thermometers have been used to measure the hotness of air across the duct and calibrated copperconstantan thermocouples (28 SWG) have been used to measure the local hotness of the absorber dishes. The digital thermometers are inserted at the bottom side of the duct, the location of a digital thermometer for air hotness measurement as shown in Figure 7. Thermocouples wires passing through the connector were connected to the selector switch through copper connecting wires (28 SWG). Temperatures reading were noted from the digital display of the micro-voltmeter, calibrated for copper-constantan thermocouples. The digital micro-voltmeter is capable of displaying the temperature values in the Celsius scale with the least count of $0.1^{\circ} \mathrm{C}$. Thermocouples were soldered on the absorber dishes at six divisions. The location of thermocouples in smooth and 3-sides synthetically rugged SAH ducts has been exposed in Figure 8.

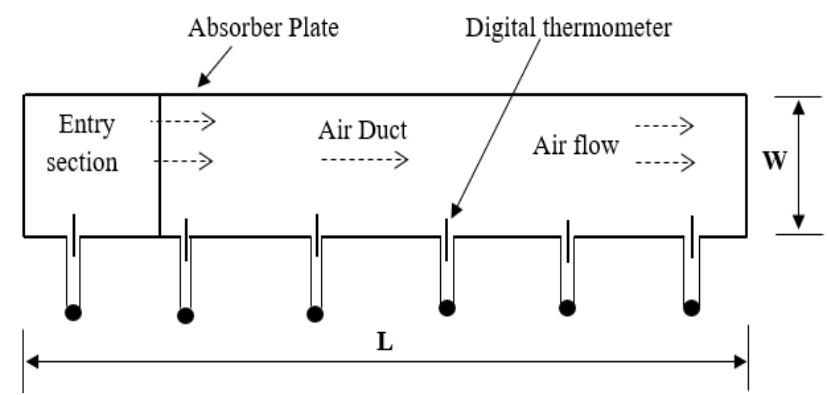

Figure 7. Location of digital thermometer on the air duct.

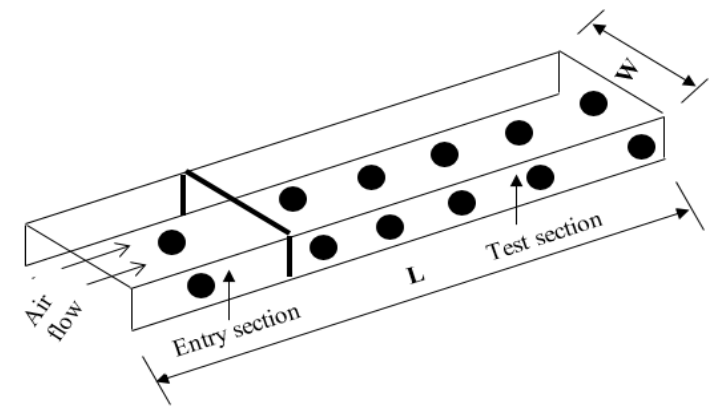

Figure 8. Location of thermocouples in smooth and three side's rugged collector.

\subsection{Measurement of Intensity of Solar Radiation}

The intensity of stellar emission (Insolation) on horizontal apparent was measured with the help of a digital pyranometer system having no errors as shown in Figure 9. The reading of solar emission, wind speed, ambient air hotness, and meteorological pressure was taken in terms of $\mathrm{W} / \mathrm{m}^{2}, \mathrm{~m} / \mathrm{s},{ }^{\circ} \mathrm{C}$ and $\mathrm{N} / \mathrm{m}^{2}$ respectively from the digital display of pyranometer.

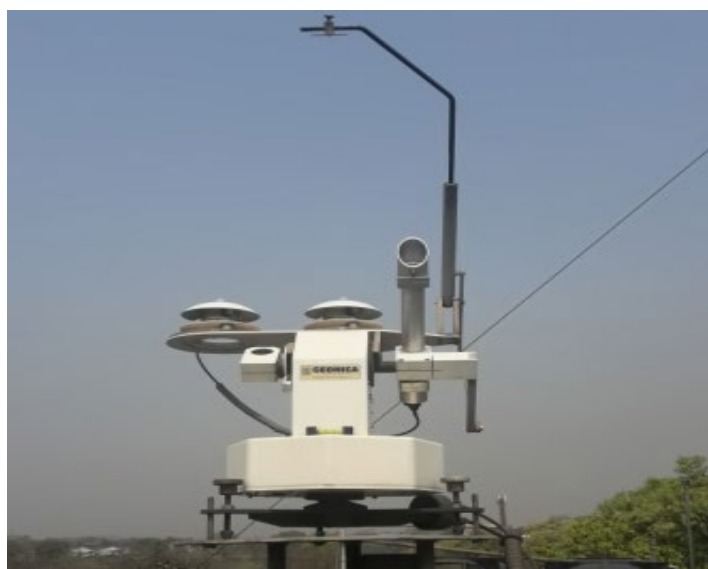

Figure 9. Photographic representation of digital pyranometer.

\section{Mathematical Formulation}

The tentative data for absorber plate and air hotness at numerous locations in the duct was noted under steady-state circumstances for given heat flux and mass stream level of air. The data was recycled to compute the heat allocation rate of air streaming in the conduit, to appraisal the Nusselt number $(\mathrm{Nu})$ and friction feature (f) on the effect of raggedness geometry and occupied constraints on heat transmission and friction features.

Consequent equations have been used for valuation the numerical morals of mass stream rate $(\dot{\mathrm{m}})$, useful heat gain $\left(Q_{u}\right)$, heat transfer coefficient $(h)$, Nusselt number $(\mathrm{Nu})$, Reynolds number ( $\mathrm{Re}$ ) and friction feature (f) were attained by adopting the tentative annotations as described in the subsequent steps.

The mass stream rates $(\dot{m})$ have been determined from the pressure descent measurement across the orifice plate [5]:

$$
\begin{gathered}
\dot{\mathrm{m}}=\mathrm{C}_{\mathrm{d}} \mathrm{xA}_{\mathrm{o}}\left[2 \mathrm{x} \rho\left(\Delta \mathrm{P}_{0}\right) /\left(1-\beta^{4}\right)\right]^{0.5} \\
\text { Where, } \Delta \mathrm{P}_{0}=\rho_{1} \times \mathrm{g} \times \Delta \mathrm{h}_{1}
\end{gathered}
$$

The rate of heat gain $\left(Q_{u}\right)$ by the air and heat transfer coefficient $(\mathrm{h})$ for smooth and 3-sides synthetically rugged solar air collectors can be resolute by adopting equivalence (3) as written under [15]:

$$
\mathrm{Q}_{\mathrm{u}}=\dot{\mathrm{m}} \times \mathrm{C}_{\mathrm{p}}\left(\mathrm{t}_{0}-\mathrm{t}_{\mathrm{i}}\right)=\mathrm{h} \times \mathrm{A}_{\mathrm{p}}\left(\overline{\mathrm{t}}_{\mathrm{p}}-\overline{\mathrm{t}}_{\mathrm{f}}\right)
$$

Average value of plate hotness $\left(\bar{t}_{p}\right)$ was resolute from the detailed hotness profile of the absorber plate indicated by six thermocouples at numerous locations [15]:

$$
\bar{t}_{\mathrm{p}}=\frac{\mathrm{t}_{\mathrm{p} 1}+\mathrm{t}_{\mathrm{p} 2}+\mathrm{t}_{\mathrm{p} 3}+\mathrm{t}_{\mathrm{p} 4}+\mathrm{t}_{\mathrm{P} 5}+\mathrm{t}_{\mathrm{p} 6}}{6}
$$

The average value of fluid hotness $\left(\bar{t}_{\mathrm{f}}\right)$ was resolute from the detailed hotness profile of air in the conduit by six digital 
thermometers at numerous locations in the test segment of the duct [15]:

$$
\bar{t}_{f}=\frac{t_{f 1}+t_{f 2}+t_{f 3}+t_{f 4}+t_{f 5}+t_{f 6}}{6}
$$

The Nusselt number $(\mathrm{Nu})$ for smooth and three-side's rugged SAH applying equivalence (6) written below [16]:

$$
\mathrm{Nu}=\frac{\mathrm{h} \times \mathrm{D}}{\mathrm{k}}
$$

The friction feature (f) was resolute from the flow velocity of air $(\mathrm{v})$ and pressure bead $\left(\Delta \mathrm{P}_{\mathrm{d}}\right)$ across the conduit of the test division adopting the Darcy-Wiesbach Eq. (7) inscribed below [5]:

$$
\mathrm{f}=\frac{2 \times\left(\Delta \mathrm{P}_{\mathrm{d}}\right) \times \mathrm{D}}{4 \times \rho \times \mathrm{L} \times \mathrm{V}^{2}}
$$

Hydraulic diameter, $D=\frac{4 \mathrm{~W} \times \mathrm{H}}{2(\mathrm{~W}+\mathrm{H})}$

Pressure bead across the conduit, $\Delta \mathrm{P}_{\mathrm{d}}=\rho_{2} \times \mathrm{g} \times\left(\Delta \mathrm{h}_{2}\right)$

The absorber plate area $\left(A_{p}\right)$ in equivalence (3) is the summation of the top collector area and two side collector area for three sides rugged and smooth SAH conduit as written under [15]:

$$
A_{p}=L \times W+2(L \times H)
$$

Where,

$\mathrm{L}=$ Length of the collector

$\mathrm{W}=$ Width of the absorber plate

$\mathrm{H}=$ Height of the duct.

\section{Results and Discussion}

The rigorous tentative work has been accomplished and data for both smooth and three-side rugged SAHs have been recorded simultaneously at changing morals of stream Reynolds number (Re). For three sides rugged solar air heaters taking an arrangement of a combination of multi-v and transverse wire (top wall multi-v and two side walls transverse) with the trial constraints, at relative raggedness pitch, $\mathrm{P} / \mathrm{e}$, in the range of $10-25$, relative raggedness height, $\mathrm{e} / \mathrm{D}$, in the range of $0.018-0.042$, at the immovable value of angle of attack, $\alpha$, equal to $60^{\circ}$, have been tested and compare the results over smooth solar air collector. Data has been collected at six different values of mass stream rates $(\operatorname{Re}=3500-12,000)$ for each conduit with specific raggedness elements. At higher value of mass stream rate $(\operatorname{Re}>12,000)$ there is not much difference of heat transfer coefficient between the smooth and three-side rugged duct. This is due to the fact that at greater mass stream rates, air travels quickly inside the duct and it does not get sufficient time to get affected by the raggedness provided inside the duct. The entire tentative inquiry has been carried out under actual outdoor circumstances for which measure the pressure bead across orifice meter, pressure bead across the duct, hotness along the absorber dish, air hotness at the inlet and the outlet of the conduits and the intensity of incident solar contamination [30]. During a specific day intensity of solar emission varied from $709-919 \mathrm{~W} / \mathrm{m}^{2}$ and ambient hotness varied from $36.9-41.7^{\circ} \mathrm{C}$.

The variant of solar emission and climate temperature on a typical day concerning time during the trial period inbetween 11:00-14: 00 hour, as shown in Figure 10. It is clear from the figure as the day movement, the emission of solar intensity rises curiously up to 11:45 hour, after then it falls occasionally. As far as the ambient temperature is concerned, it grows monotonously. It is found that the maximum value of solar emission is $919 \mathrm{~W} / \mathrm{m}^{2}$ and climate temperature is $41.7^{\circ} \mathrm{C}$ on a single day. The variant in a plate and air temperature for smooth and three side's synthetically roughed solar collector along the trial length is exposed in Figure 11. It has been realized that the expansion in air temperature for three side's rugged duct is higher as compared to the smooth plate. Meantime, for plate temperature in three sides roughed ducts practice more temperature upsurge than that of smooth one due to marginal heat transferal to the under flowing fluid (air) along the test length of the collector. From the figure, it is clear that plate and air temperature both are greater in three side's rugged collectors than those of smooth ones and also observed that plate hotness falls and the air hotness rises along the test length of the collector.

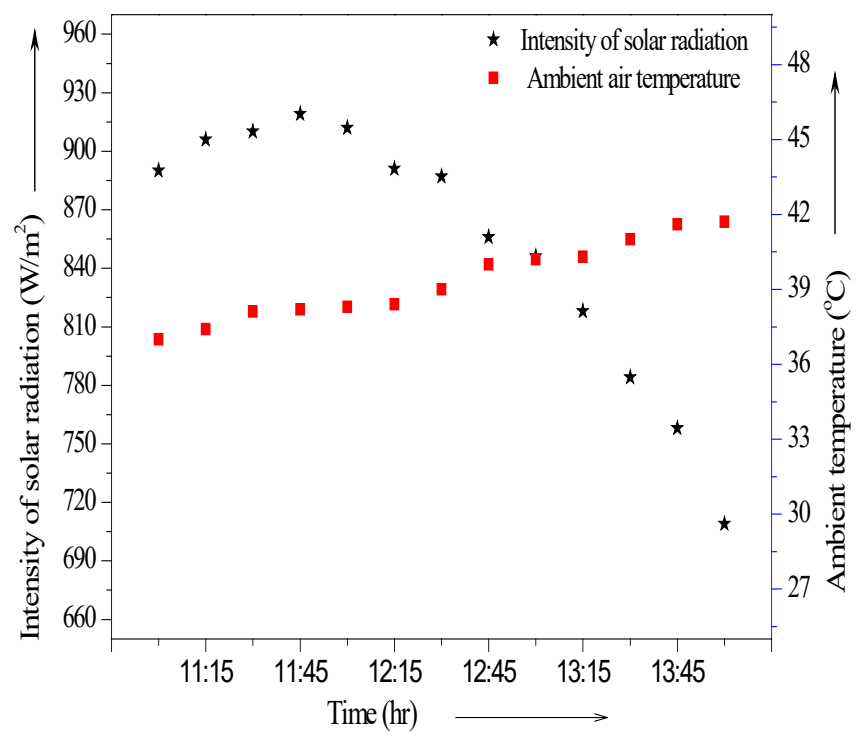

Figure 10. Variation of solar insolation and ambient temperature during a day.

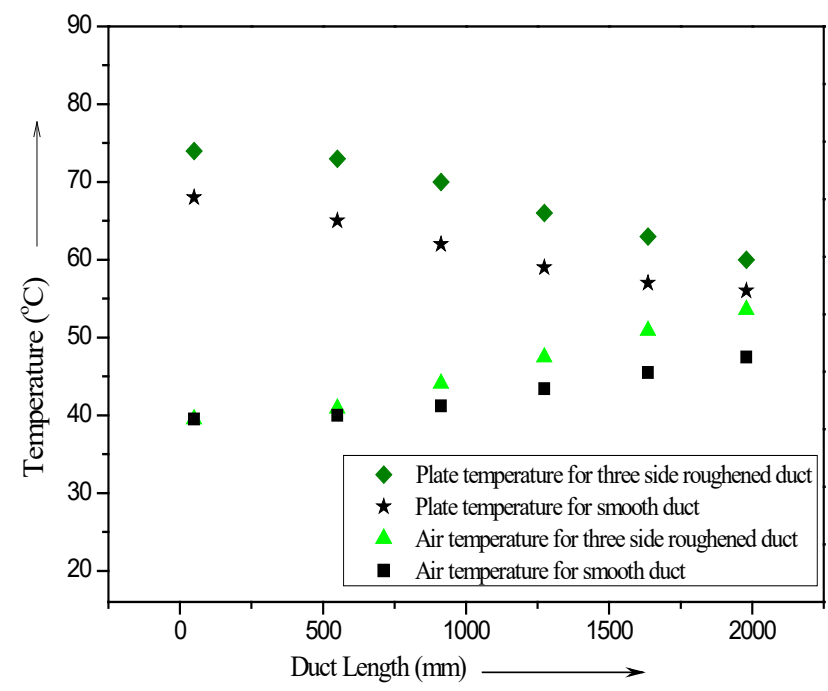

Figure 11. Variation of plate and fluid temperature

\subsection{Validation of Experimental Set-up}

To validation of experimental data, the trial values of Nusselt number $(\mathrm{Nu})$ and friction feature (f) for both smooth and 3 -sides rugged duct were computed, the computed 
records for a smooth collector is equated with the standards achieved by using Dittus-Boelter equation [16] and Modified-Blasius equation [16] for Nusselt number and friction feature as given in equation (11) and (12) respectively.

$$
\begin{aligned}
& \mathrm{Nu}_{\mathrm{s}}=0.023 \mathrm{Re}^{0.8} \mathrm{P}_{\mathrm{r}}^{0.4} \\
& \mathrm{f}_{\mathrm{s}}=0.085(\mathrm{Re})^{-0.25}
\end{aligned}
$$

The tentative and expected standards of the Nusselt number and friction feature as an operation of Re have been exposed in Figures 12 and 13 respectively for a smooth absorber dish. The mean aberration of trial morals of Nusselt number is $\pm 2.3 \%$ from the expected morals as given in equation (11) and the mean aberration of trial morals of friction feature is $\pm 2.6 \%$ from the expected morals as given in equation (12). Thus, a really good settlement among trial and expected values confirms the correctness of data composed with the experimental set-up.

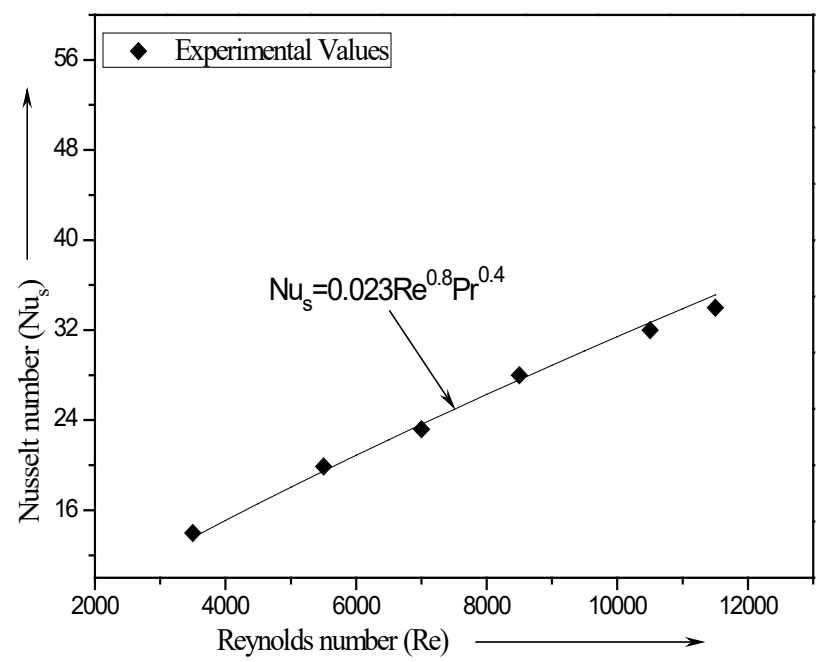

Figure 12. Validation of tentative work for $\mathrm{Nu}$.

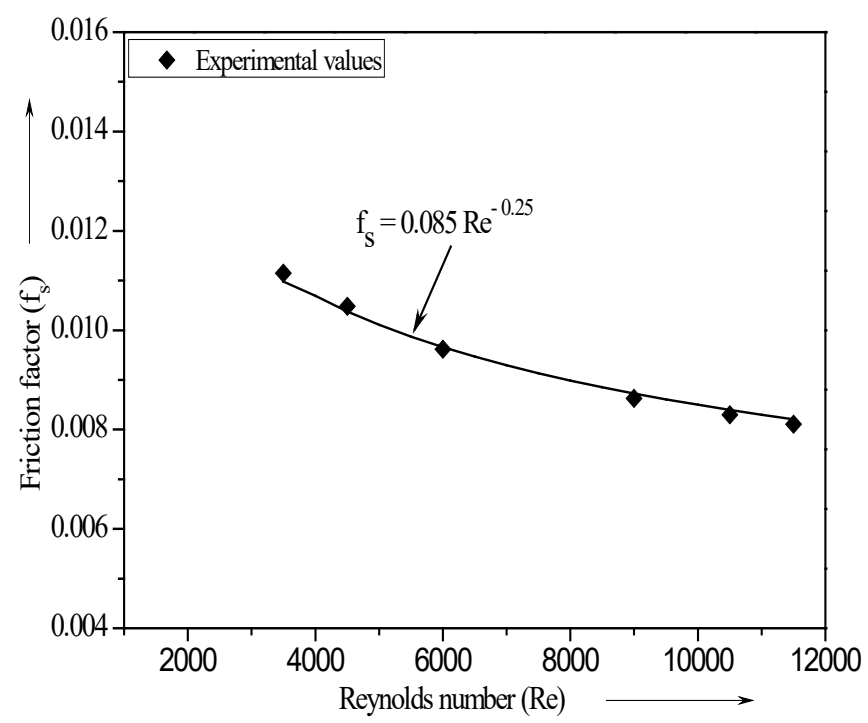

Figure 13. Validation of tentative work for $f$.

\subsection{Results on Nusselt number and Friction factor}

Figures 14 and 15 have been exposed to understand the influence of irregularity and flow specification on heat transmission improvement in three sides rugged $\mathrm{SAH}$ as identification to plane ones at varying values of flow
Reynolds number. It is clear from both figures Nusselt number increases in smooth and three sides rugged collector with an increase in Reynolds number due to a rise in turbulent force affected by a rise in turbulent kinetic energy and turbulent dissipation rate.

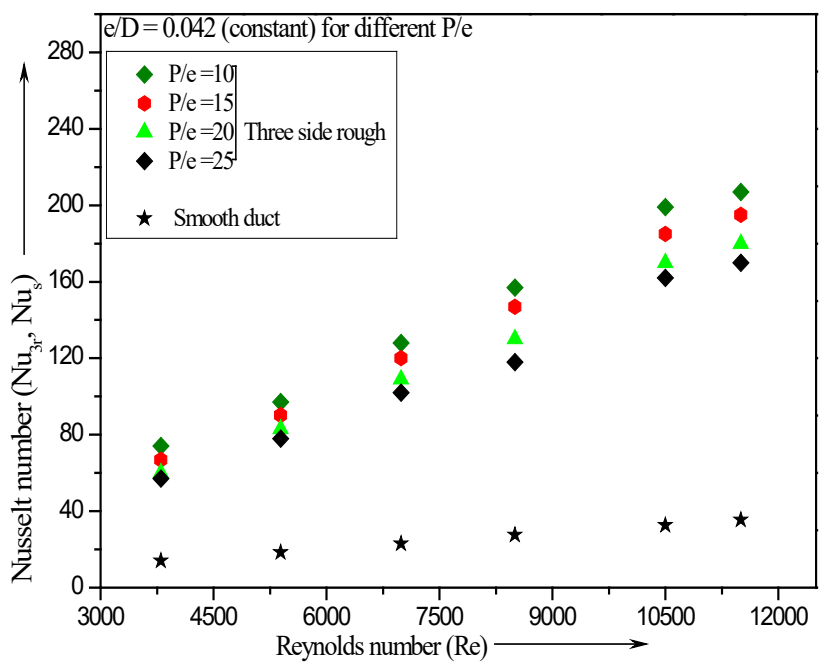

Figure 14. Effect of P/e on Nusselt number for various morals of Re.

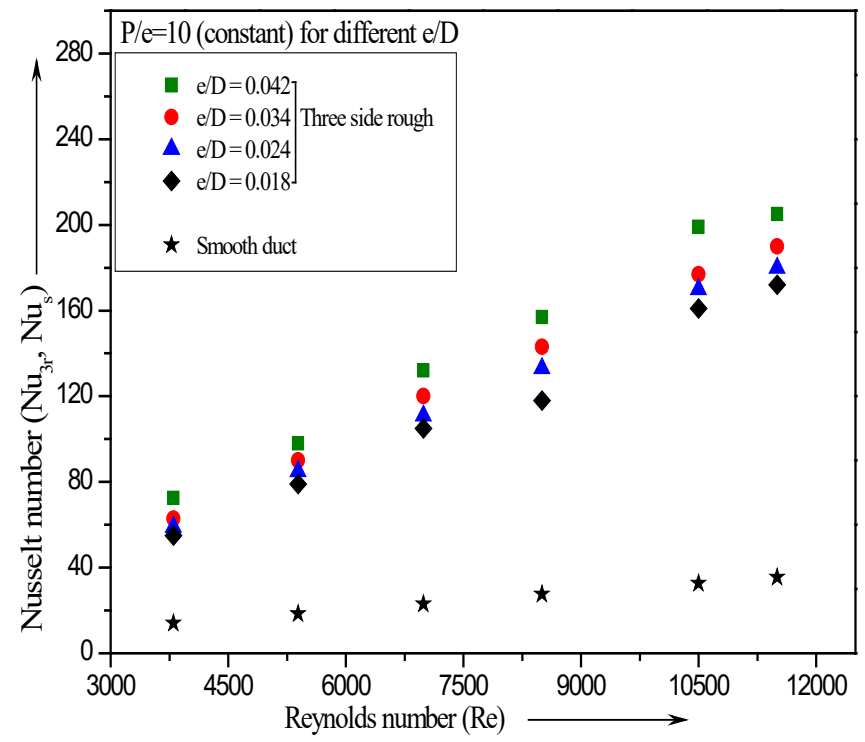

Figure 15. Effect of e/D on Nusselt number for various morals of Re.

Figure 14 shows the outcome of the effect of relative raggedness pitch, $\mathrm{P} / \mathrm{e}$, on Nusselt number $\mathrm{Nu}_{3 \mathrm{r}}$ for three side's rugged collectors and for $\mathrm{Nu}_{\mathrm{s}}$ plane ones, for given morals of $\mathrm{e} / \mathrm{D}=0.042$, and $\alpha=60^{\circ}$. It is clear from the figure heat allocation rate upsurges with reducing the morals of $\mathrm{P} / \mathrm{e}$, due to reduces the distance of the reattachment point, break laminar sub-layer and generate local wall turbulence, as a result thermal resistance reduces and greatly heat transmission rate enhance. The maximum heat transmission can occur at $\mathrm{P} / \mathrm{e}=10$. The morals of Nusselt number for 3side's rugged collector enrich by an extant of $4.07-6.42$ times as related to plane ones. Figure 15 indicates the effect of relative raggedness height, e/D, on $\mathrm{Nu}_{3 \mathrm{r}}$ for 3-sides rugged collector and $\mathrm{Nu}_{\mathrm{s}}$ for plane ones, for given morals of $\mathrm{P} / \mathrm{e}=10$ and $\alpha=60^{\circ}$. It is identified that the heat transferal rate rises with rising the values of $\mathrm{e} / \mathrm{D}$, due to the violation and re-attachment of the laminar sub-layer near 
downstream of flow. The occurrence of continual rib causes much more turbulence in the run path, which results in significant growth in $\mathrm{Nu}$ and entire thermal achievement. The morals of Nusselt number for three side's rugged collectors enrich by the extent of $3.80-5.98$ times over the plane ones and higher heat transfer can occur at $\mathrm{e} / \mathrm{D}=0.042$.

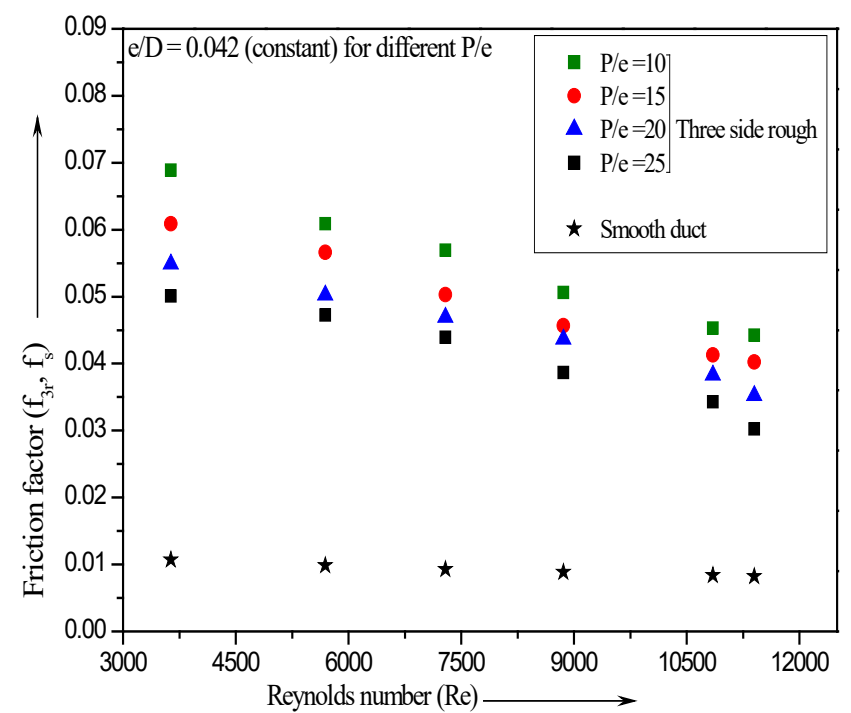

Figure 16. Effect of P/e on friction factor for various values of Re.

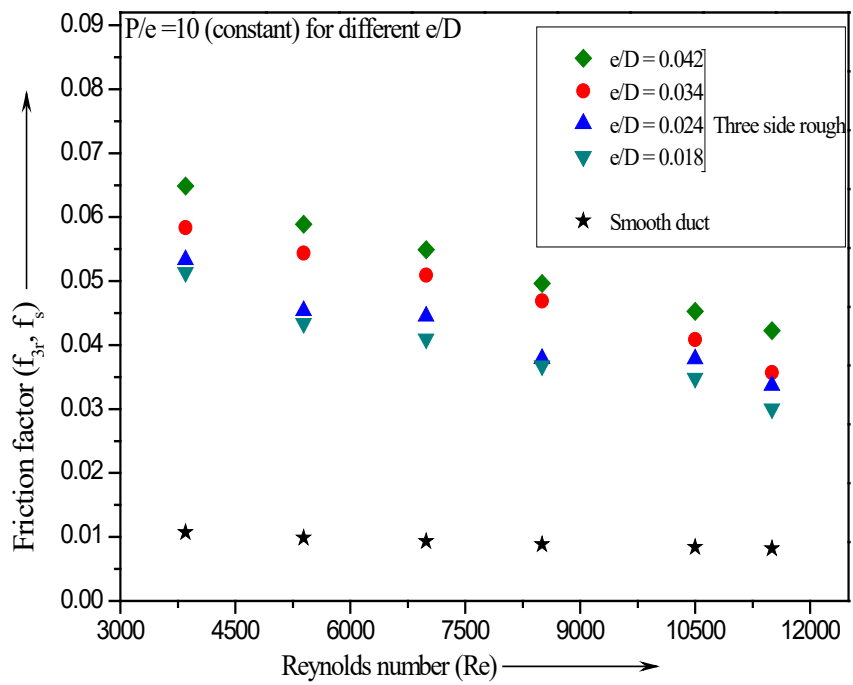

Figure 17. Effect of e/D on friction factor for various values of Re.

Figures 16 and 17 indicate the inspiration of flow specification on the friction features in smooth and three sides rugged SAHs at varying values of Re. It is cleared from the both figures friction feature decreases in smooth and three-side rugged collector with an increase in $\mathrm{Re}$ due to destruction of viscous sub-layer. Figure 16 illustrates the consequence of relative raggedness pitch, $\mathrm{P} / \mathrm{e}$, on $\mathrm{f}_{3 \mathrm{r}}$ for three sides rugged collector and $\mathrm{f}_{\mathrm{s}}$ for flat plate collector, for given morals of $\mathrm{e} / \mathrm{D}=0.042$, and angle of attack, $\alpha=60^{\circ}$. The friction factor is higher for lower the value of $\mathrm{P} / \mathrm{e}$. The morals of the friction feature in three side's rugged collector enrich by an extent of $3.68-6.44$ times as compared to plain ones. Figure 17 illustrates the outcome of relative raggedness height, $e / D$, on $f_{3 r}$, for 3-side's rugged collector and $f_{s}$ for the smooth collector, for given standards of $\mathrm{P} / \mathrm{e}=10$ and $\alpha=60^{\circ}$. The friction feature is higher for a higher value of e/D. The standards of friction feature $f_{3 r}$ in 3-side's rugged solar air collector upsurge by an extent of $3.65-6.06$ times as related to the smooth collector.

\subsection{Heat Transfer Enhancement}

Heat transfer enhancement ratio Nusselt number for three sides synthetically rugged $\mathrm{SAH}$ to that of smooth plate SAHs $\left(\mathrm{Nu}_{3 \mathrm{r}} / \mathrm{Nu}_{\mathrm{s}}\right)$ versus Reynolds number $(\mathrm{Re})$, for varying values of relative roughness pitch $(\mathrm{P} / \mathrm{e}=10,15,20$ and 25); and relative roughness height $(\mathrm{e} / \mathrm{D}=0.018,0.024$, 0.032 and 0.042 ); at an angle of attack, $\alpha=60^{\circ}$ are indicated in Figures 18 and 19 respectively. Whereas the standards of $\mathrm{Nu}$ for three side rugged $\left(\mathrm{Nu}_{3 \mathrm{r}}\right)$ and for smooth absorber plate $\left(\mathrm{Nu}_{\mathrm{s}}\right)$ have been operated out using equations (13) and (14) respectively

$$
\begin{aligned}
& \mathrm{Nu}_{3 \mathrm{r}}=\frac{\mathrm{h}_{3 \mathrm{r}} \times \mathrm{D}}{\mathrm{k}} \\
& \mathrm{Nu}_{\mathrm{s}}=\frac{\mathrm{h}_{\mathrm{s}} \times \mathrm{D}}{\mathrm{k}}
\end{aligned}
$$

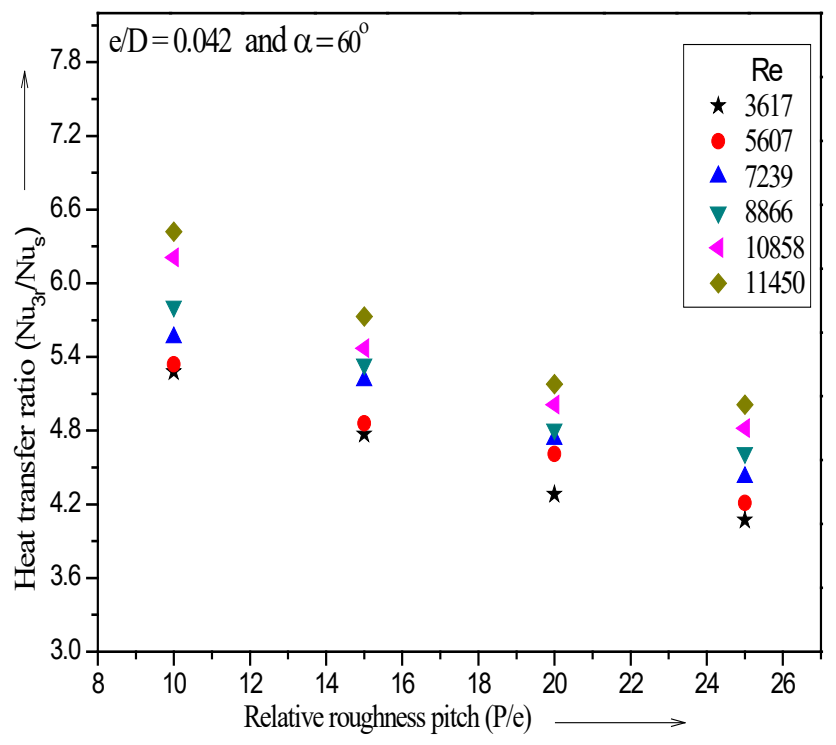

Figure 18. Heat transfer augmentation ratio versus $P / e$.

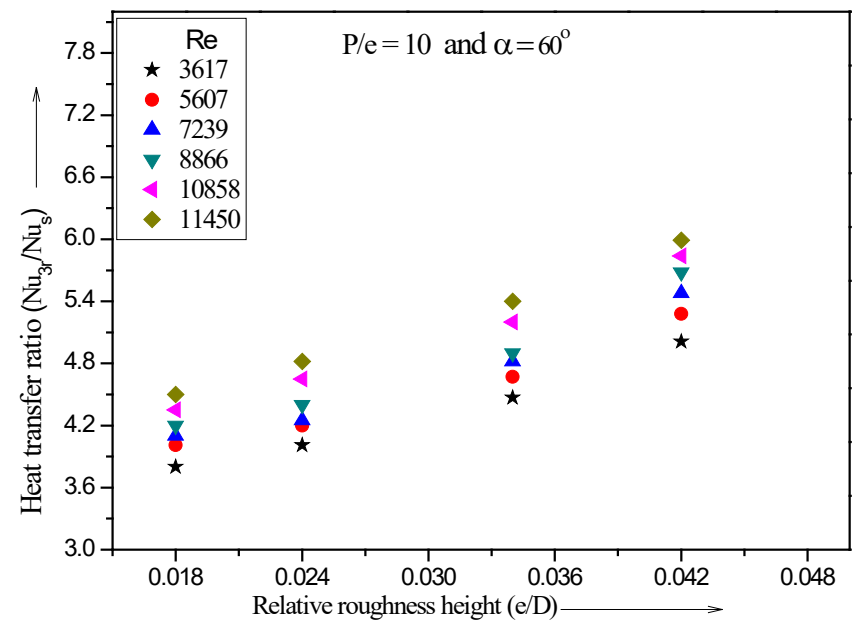

Figure 19. Heat transfer augmentation ratio versus e/D.

The percentage increment on heat transfer enrichment ratio is more at greater standards of Re and greater morals of the intensity of solar emission. Figure 18 indicates that the heat transferal ratio decreases with increasing values of relative raggedness pitch $(\mathrm{P} / \mathrm{e})$. In three side's rugged solar collectors 
heat transferal enhancement ratio upsurges to an extent of $4.07-6.42$ times over those of plane ones, and higher heat with rising standards of relative raggedness height (e/D). It is concluded that in three sides rugged solar collectors heat relocation enhancement ratio rises to an extent of $3.80-$ 5.98 times over those of plain ones and maximum heat transmission enrichment ratio can occur at $\mathrm{e} / \mathrm{D}=0.042$. It could, therefore, be resolved that 3-side's rugged solar air heaters are thermally superior to those of flat plate solar air heaters and can thermally achieve even superior at higher standards of mass stream proportion and intensity of solar radiation

\section{Conclusion}

The instant paper appearance the utility of heat replacement augmentation using three side's rectangular duct solar collectors taking an arrangement of multi-v and transverse wire rib roughness on the absorber plate, covered with glass on three sides and subjected to unvarying heat flux. Heat transmission coefficient and friction feature resolved provisionally, air as the streaming fluid for Reynolds number, Re, ranges from $3500-12,000$. Based on the experimental outcomes subsequent conclusions are drawn:-

- The complete experimental study is carried out under actual open-air conditions in which solar insolation varied from $709-919 \mathrm{~W} / \mathrm{m}^{2}$ and ambient temperature varied from $36.9-41.7{ }^{\circ} \mathrm{C}$ during a particular day. The maximum enrichment of air temperature in three side's rugged solar collectors is found to be $54.47 \%$ over that of smooth ones, at relative raggedness pitch, $\mathrm{P} / \mathrm{e}$, value of 10 ; relative raggedness height, e/D, value of 0.042 and flow attack angle, $\alpha$, equal to $60^{\circ}$.

- The useful heat gain by air flowing under the absorber plate, the fluid (air) temperature from inlet to outlet increases while plate temperature from inlet to outlet decreases. The plate and air temperature both are higher in three side's rugged collectors as related to smooth ones.

- The morals of heat transmission coefficient increases and friction feature shrinkages with the rising standards of Reynolds number and depends upon the relative raggedness pitch $(\mathrm{P} / \mathrm{e})$ and relative raggedness height (e/D).

- The values of heat transmission and friction feature both are raises with rising standards of $\mathrm{e} / \mathrm{D}$ and shrinkage with rising standards of $\mathrm{P} / \mathrm{e}$. The maximum heat transfer and friction factor can occur at relative raggedness pitch, $\mathrm{P} / \mathrm{e}$, value of 10 , and relative raggedness height, e/D, value of 0.042 .

- The values of heat transmission coefficient and friction feature in three sides artificially rugged solar collectors are enhanced by an amount of $3.80-6.42$ and $3.65-6.44$ times respectively over that of the smooth solar collectors for the collection of specification inspected.

- Therefore, it could be achieved that three side's rugged solar collectors are thermally more suitable related to smooth one and can thermally implement even well at greater standards of mass stream rate and solar insolation. allocation enrichment ratio can occur at $\mathrm{P} / \mathrm{e}=10$. Figure 19 indicates that heat obligation enhancement ratio growths

\section{References}

[1] J.S. Hsiesh, "Solar energy engineering", New Jersey, Prentice Hall. 1986.

[2] D. Kumar and L. Prasad, "Heat Transfer Augmentation of Various Roughness Geometry Used in Solar Air Heaters", International Journal of Mechanical Engineering and Technology, 8(12), pp 491-508, 2017.

[3] G.N. Tiwari, "Fundamentals Design Modelling and Application", Narosa Publication, Solar Energy, 2008.

[4] A.M.E. Momin, J.S. Saini, S.C. Solanki, "Heat transfer and friction in solar air heater duct with v-shaped rib roughness on absorber plate", International Journal of Heat Mass Transfer, 45, pp 3383-3396, 2002.

[5] V.S. Hans, R.P. Saini, J.S. Saini, "Heat transfer and friction factor correlations for a solar air heater duct roughened artificially with multiple v-ribs", Solar Energy, 84, pp 898-911, 2010.

[6] J.P. Holman, "Experimental Method for Engineers", McGraw Hill Book Company, New York, 2007.

[7] B.N. Prasad and J.S. Saini, "Effect of artificial roughness on heat transfer and friction factor in a solar air heater", Solar Energy, 41(6), pp 555-560, 1988.

[8] R.L. Webb, and E.R.G. Eckert, "Application of rough surfaces of heat exchanger design", International Journal of Heat Mass Transfer, 5, pp 1647-1658, 1972

[9] D. Kumar and L. Prasad, "Analysis on Optimal Thermohydraulic Performance of Solar Air Heater Having Multiple V-shaped Wire Rib Roughness on Absorber Plate”, International Energy Journal, 18, pp 153-170, 2018.

[10] J. C. Han, L. R. Glicksman, W.M. Rosenow, "Investigation of heat transfer and friction for rib roughened surfaces", International Journal of Heat Mass Transfer, 21, pp 1143-1156, 1978.

[11] M.E. Taslim, T. Li, D.M. Kerche, "Experimental heat transfer and friction in channel roughened with angled v-shaped and discrete ribs on two opposite walls", Journal Turbo-machinery, ASME, 118, pp 20-28, 1996.

[12] X. Goa and B. Sunden, "Heat transfer and pressure drop measurement in rib roughened rectangular ducts", Experimental Thermal and Fluid Science, 124, pp 2534, 2001.

[13] R.P. Saini and J.S. Saini, "Heat transfer and friction factor correlations for artificially roughened ducts with expanded metal mesh as roughened element", International Journal of Heat Mass Transfer, 40, pp 973-86, 1997.

[14] B.N. Prasad, A. Kumar, K.D.P. Singh, "Optimization of Thermo-hydraulic performance in three sides artificially roughened solar air heaters", Solar Energy, 111, pp 313-319, 2015.

[15] A.K. Behura, B.N. Prasad, L. Prasad, "Heat transfer, friction factor and thermal performance of three sides artificially roughened solar air heaters", Solar Energy, 130, pp 46-59, 2016.

[16] N.S. Deo, S. Chander, J.S. Saini, "Performance analysis of solar air heater duct roughened with multigap v-down ribs combined with staggered ribs", Renewable Energy, 91, pp 484-500, 2016.

[17] M.M. Sahu and J.L. Bhagoria, "Augmentation of heat transfer coefficient by using $90^{\circ}$ broken transverse ribs on absorber plate of solar air heater", Renewable 
Energy, 30, pp 2057-2063, 2005.

[18] R. Karwa, S. C. Solanki, J.S. Saini, “Thermo-hydraulic 26, pp 161-176, 2001.

[19] ASHRAE Standard 93-97. (1977). "Method of Testing to determine the thermal performance of solar collectors", New York.

[20] R. Karwa and G. Chitoshiya, "Performance study of solar air heater having v-down discrete ribs on absorber plate", Energy, 55, pp 939-955, 2013.

[21] A. Layek, J.S. Saini, S.C. Solanki, "Second law optimization of a solar air heater having chamfered ribgroove roughness on absorber plate", Renewable Energy, 32, pp 1967-1980, 2007.

[22] D. Kumar and L. Prasad, "Thermo-hydraulic performance of solar air heater having multiple vshaped rib roughness on absorber plates", Carbon Science and Technology, 10(1), pp 39-50, 2018.

[23] S. Sharma, M. Patel, N.K, Mehta, "Computational heat transfer analysis of electronic equipment", International Journal of Mechanical Engineering and Technology, 10(7), pp 141-149, 2019.

[24] V. Kumar, and L. Prasad, "Thermal performance investigation of three sides concave dimple roughened solar air heater", Solar Energy, 188, pp 361-379, 2019.

[25] A. Perwez and R. Kumar, "Thermal performance investigation of the flat and spherical dimple absorber plate solar air heaters", Solar Energy, 193, pp 309-323, 2019.

[26] S.J. Kline and F.A Mc Clintok, "Describing uncertainties in single sample experiment", Mechanical Engineering, 75, pp 3-8, 1953.

[27] A. Kumar and A. Layek, "Energetic and exegetics performance evaluation of solar air heater with twisted rib roughness on absorber plate", Journal of Cleaner Production, 232, pp 617-628, 2019.

[28] J.C. Han, "Heat transfer and friction characteristics in rectangular channels with rib turrbulators", ASME Journal of Heat Transfer, 110, pp 321-328, 1988.

[29] V. Kumar and L. Prasad, "Experimental Investigation on Heat Transfer and Fluid Flow of Air Flowing Under Three Sides Concave Dimple Roughened Duct", International Journal of Mechanical Engineering and Technology, 8(11), pp 1083-1094, 2017.

[30] V. Kumar, "Thermal and thermohydraulic performance analysis of three sides artificially roughened solar collectors", Solar Energy, 190, pp 212-227, 2019. performance of solar air heaters having integral chamfered rib roughness on absorber plates", Energy,

\section{Nomenclature}

$A_{p} \quad$ surface area of absorber plate, $m^{2}$

$A_{o} \quad$ area of orifice plate $m^{2}$

$\mathrm{C}_{\mathrm{p}} \quad$ specific heat of air at constant pressure, $\mathrm{J} / \mathrm{kg} \mathrm{K}$

$\mathrm{D}$, hydraulic diameter of stellar air heater,

$$
\mathrm{D}=4 \mathrm{WH} / 2(\mathrm{~W}+\mathrm{H}), \mathrm{m}
$$

e synthetic raggedness height, $\mathrm{m}$

$\mathrm{H}$ height of the duct, $\mathrm{m}$

h convective heat transfer coefficient, $W / \mathrm{m}^{2} \mathrm{~K}$

$\Delta \mathrm{h}_{1}$ height of $\mathrm{U}$-tube manometer fluid column, $\mathrm{m}$

$\Delta \mathrm{h}_{2}$ height of micromanometer fluid column, $\mathrm{m}$

I intensity of solar radiation $W / \mathrm{m}^{2}$

$\mathrm{k}$ thermal conductivity of air $\mathrm{W} / \mathrm{mK}$

$\mathrm{L}$ length of test section, $\mathrm{m}$

$\dot{\mathrm{m}}$ mass flow rate of air, $\mathrm{Kg} / \mathrm{s}$

$\mathrm{P}$, raggedness pitch, $\mathrm{m}$

$\Delta \mathrm{P}_{\mathrm{O}}$ pressure difference of manometric fluid level in U-tube manometer, $\mathrm{P}_{\mathrm{a}}$

$\Delta \mathrm{P}_{\mathrm{d}}$ pressure difference of water column level in micro-manometer, $\mathrm{P}_{\mathrm{a}}$

$\mathrm{Q}_{\mathrm{u}} \quad$ useful heat gain, $\mathrm{W}$

$\mathrm{Q}_{3 \mathrm{r}}$ useful heat gain for three-sides roughness, $\mathrm{W}$

$\mathrm{t}_{\mathrm{a}}$ ambient temperature, $\mathrm{K}$

$t_{o} \quad$ outlet temperature of fluid, $\mathrm{K}$

$t_{i} \quad$ inlet temperature of fluid, $\mathrm{K}$

$\overline{t_{p}} \quad$ mean plate temperature, $\mathrm{K}$

$\overline{\mathrm{t}_{\mathrm{f}}} \quad$ mean fluid temperature, $\mathrm{K}$

$\mathrm{v}$ velocity of air inside the duct, $\mathrm{m} / \mathrm{s}$

W width of duct, $m$

\section{Dimensionless parameters}

$\mathrm{f}_{3 \mathrm{r}}$ average friction factor for thee sides rough

$\mathrm{f}_{s}$ average friction factor for smooth

$\mathrm{f}$ friction factor

e/D, relative raggedness height

$\mathrm{Nu}$ Nusselt number

$\mathrm{Nu}_{3 \mathrm{r}}$ average Nusselt number for three sides rough

$\mathrm{Nu}_{\mathrm{s}}$ average Nusselt number for smooth

$\mathrm{P} / \mathrm{e}$ relative raggedness pitch

$\mathrm{W} / \mathrm{H}$ duct aspect ratio

Re Reynolds number 